\title{
Open source 3D printers: an appropriate technology for building low cost optics labs for the developing communities
}

\section{J. Gwamuri, Joshua Pearce}

J. Gwamuri, Joshua M. Pearce, "Open source 3D printers: an appropriate technology for building low cost optics labs for the developing communities," Proc. SPIE 10452, 14th Conference on Education and Training in Optics and Photonics: ETOP 2017, 104522S (16 August 2017); doi: 10.1117/12.2269852

SPIE Event: 14th Conference on Education and Training in Optics and Photonics, ETOP 2017, 2017, Hangzhou, China 


\title{
Open Source 3-D Printers: An Appropriate Technology for Building Low Cost Optics Labs for the Developing Communities
}

\author{
J. Gwamuri*a, b, Joshua M. Pearce ${ }^{\mathrm{b}, \mathrm{c}}$ \\ ${ }^{a}$ Department of Applied Physics, National University of Science \& Technology, Bulawayo, \\ Zimbabwe; ${ }^{b}$ Department of Materials Science \& Engineering, Michigan Technological University, \\ Houghton, MI, USA; ${ }^{c}$ Department of Electrical and Computer Engineering, Michigan \\ Technological University, Houghton, MI, USA
}

\begin{abstract}
The recent introduction of RepRap (self-replicating rapid prototyper) 3-D printers and the resultant open source technological improvements have resulted in affordable 3-D printing, enabling low-cost distributed manufacturing for individuals. This development and others such as the rise of open source-appropriate technology (OSAT) and solar powered 3-D printing are moving 3-D printing from an industry based technology to one that could be used in the developing world for sustainable development. In this paper, we explore some specific technological improvements and how distributed manufacturing with open-source 3-D printing can be used to provide open-source 3-D printable optics components for developing world communities through the ability to print less expensive and customized products. This paper presents an open-source low cost optical equipment library which enables relatively easily adapted customizable designs with the potential of changing the way optics is taught in resource constraint communities. The study shows that this method of scientific hardware development has a potential to enables a much broader audience to participate in optical experimentation both as research and teaching platforms. Conclusions on the technical viability of 3-D printing to assist in development and recommendations on how developing communities can fully exploit this technology to improve the learning of optics through hands-on methods have been outlined.
\end{abstract}

Keywords: UNESCO, SPIE, OSA, Optics Kits, RepRap, 3-D printers, OSAT, Open-source lab, Developing world, Scientific hardware, Optics lab, Distributed manufacturing.

\section{INTRODUCTION}

It is well established that technology advancement in a particular nation or community can be directly correlated to their economic growth. Technology has been observed to affect the economy through direct job creation, contribution to GDP growth, creation of new services and industries, workforce transformation and business innovation [1]. Adoption and effective use of novel technologies has been previously linked to marketplace transformation, improved living standards and more robust international trade, hence revolutionizing virtually every industry in the economy [1]. However, there has been a pronounced and widespread lack of adoption and implementation of technology for sustainable economic growth in the developing world resulting in high levels of the persistent poverty currently besieging these communities. Several barriers have been identified as responsible for the lack of/slow adoption and implementation of technology by developing nations [2-4]. In a study conducted by Ross and Lewin [3], the lack of well-trained science workforce at all levels was singled out as the root impediment to the economic development of many resource-constrained economies. Several reasons contributing to this situation, but the most notable ones include the following: lack of well-trained science teachers, lack of innovative curriculum reforms, as well as lack of (or insufficient) resources allocated toward the teaching of science subjects in schools [3].

The lack of resources in developing countries schools (such as the basic teaching equipment required to motivate students and give them hands-on experiences from as early as elementary education stage) makes it challenging for students to appreciate science. This, in turn, hampers their ability to both master and apply science and technology later 
on in their careers as a process of contributing to the economic development of their communities [3]. To try and address this severe lack of resources and equipment for teaching science in developing world schools, many organizations, particularly the International Society of Optical Engineers (SPIE) [5], Optical Society of America (OSA) [6], United Nations Educational, Scientific and Cultural Organization (UNESCO) [4], the Goethe Institute [7], the Commonwealth Secretariat [8] and GTZ (Deutsche Gasellschatf fur Technische Zusammenarbeit) [9] have been actively working with developing world communities as early as the 1960s. Despite all these complimentary efforts, the situation remains critical for many developing world schools and the future is still bleak for many students in these communities. One way of providing high-quality learning aids is with inexpensive pre-packaged learning kits. Some of the most notable kits for teaching science are listed in Table 1, which includes the average cost of procurement, possible sources of the different kits and target areas.

Table 1. Science Kits for the developing world [10]

\begin{tabular}{|c|c|c|c|}
\hline Kit Description & Origin/ Provider/ Developed for & Cost/ Kit & Target Area/Subject (s) \\
\hline $\begin{array}{l}\text { Light Blox Kit: } \\
\text { International Year } \\
\text { of Light Edition }\end{array}$ & UNESCO & $\begin{array}{c}\text { US\$ } 49 \\
{[11]}\end{array}$ & Physics/Optics \\
\hline $\begin{array}{l}\text { Light and Laser } \\
\text { Education and } \\
\text { Outreach Kit }\end{array}$ & USA/SPIE Students Chapters & $\begin{array}{c}\text { US\$ } 199 \\
{[12]}\end{array}$ & Physics/Optics \\
\hline $\begin{array}{l}\text { Chemistry and Light } \\
\text { Kit (Variants: } \\
\text { Economic, Standard \& } \\
\text { Professional) }\end{array}$ & EU & $\begin{array}{c}\text { US\$ 266,US\$ } 665 \\
\text { \& US\$ } 1,429 \\
\text { (Euro } \\
\text { equivalent)[13] }\end{array}$ & Chemistry \\
\hline Optics Discovery Kit & USA/The Education Council of OSA & $\begin{array}{c}\text { US } \$ 37.87 \\
{[14]}\end{array}$ & $\begin{array}{l}\text { Modern Optical Sciences } \\
\text { and Engineering }\end{array}$ \\
\hline Optics Suitcase & $\begin{array}{l}\text { USA/ROSA (Rochester section of } \\
\text { OSA) }\end{array}$ & $\begin{array}{c}\text { US\$ } 350 \\
{[15]}\end{array}$ & Optics \\
\hline Photonics Explorer & EU/Eyest & $\begin{array}{c}\text { Sponsor based } \\
{[16]}\end{array}$ & STEM/Photonics \\
\hline $\begin{array}{l}\text { PhysicsQuest Kit } \\
\text { (Story based activities) }\end{array}$ & Physicscentral.com & $\begin{array}{l}\text { Free (registration } \\
\text { required) [17] }\end{array}$ & Physics \\
\hline $\begin{array}{c}\text { The Galileoscope } \\
\text { Educational Telescope } \\
\text { Kit }\end{array}$ & $\begin{array}{l}\text { Galileoscope, LLC-Astrosphere New } \\
\text { Media Association Partnership }\end{array}$ & $\begin{array}{c}\text { Donation Program } \\
{[18]}\end{array}$ & Astronomy \\
\hline $\begin{array}{l}\text { Quality Lighting } \\
\text { Teaching Kit }\end{array}$ & $\begin{array}{l}\text { U.S. National Optical Astronomy } \\
\text { Observatory (NOAO), the } \\
\text { International Dark-Sky Association } \\
\text { (IDA), the International Society for } \\
\text { Optics and Photonics (SPIE) and the } \\
\text { International Commission on } \\
\text { Illumination (CIE) Partnership }\end{array}$ & $\begin{array}{c}\text { US } \$ 230 \\
{[19]}\end{array}$ & $\begin{array}{c}\text { Illumination } \\
\text { Engineering, Energy } \\
\text { Efficiency \& Spectral } \\
\text { Properties }\end{array}$ \\
\hline
\end{tabular}

Despite the fact that the science kits listed in Table 1 have changed the lives of many students in the developing world, there are several barriers limiting the wide spread adoption of the current science kits: 1) The cost of most of these kits is 
still beyond the reach of many communities in the developing world (particularly the sub-Saharan nations who are still living in extreme poverty $[20,21]) ; 2$ ) the donation program is not effective since the donors generally decide the beneficiaries and the quantities of kits to be donated (e.g. some schools and countries may be favored at the expense of others); and 3) the kits are generic and not customized to a particular country and nation. Considering this latter barrier, as the kits do not take into account the existing curriculum, they may not reach their full potential to benefit the intended students.

To overcome these challenges, this paper leverages previous research on the use of open-source 3-D printers for economic development in resource constraint communities. The recent introduction of the RepRap (self-replicating rapid prototyper) 3-D printers $[22,24]$ has substantially reduced the costs of 3-D printers and made them widely available [25, 26] (e.g. simple RepRap kits are offered commercially on the Internet for less than US $\$ 100$ and research grade kits for US\$500). Thus, communities and schools in the developing world may now be able to afford to invest in 3-D printing technology. Free and open-source hardware (FOSH) development along with the RepRap 3-D printer models has enable 3-D printing to become a platform for promoting localized and customized distributed manufacturing [27]. Using computer aided designs (CAD), it is now possible for anyone with a 3-D printer to fabricate and customize products less expensively and faster than purchasing those [28]. With the advent of solar powered 3-D printers [29], open-source 3-D printing has the potential to substantially change the way science subjects are taught in impoverished rural communities of the developing world [30]. This model is based off of the free and open-source software (FOSS) model, which has become a standard method of software development [31,32]. FOSS provides an alternative to expensive and proprietary systems as it reduces research and development costs, and also showcases alternatives to the linear hierarchical structure used to design technology and products. Due to this tremendous success of FOSS development, the concept has spread outside of software to areas such as education [33,34], appropriate technology for sustainable development [35, 36], science [37], nanotechnology [38, 39] and medicine [40, 41]. According to a numerous studies [42-51], the rise of opensource hardware is poised to drive down the cost of doing experimental science and put state-of -the-art scientific tools in the hands of everyone.

To aid in that transition, in this study the potential of RepRap 3-D printers is investigated for the development of opensource lab kits in general and optics kits in particular to radically reduce the cost of research and science education in the developing world nations. First, a brief introduction to existing libraries [31] of open-source 3-D-printable optics equipment is presented. These library can be used as a flexible, low-cost public-domain tool set for developing both research and teaching optics hardware. Secondly, a description of the use of parametric open-source designs using an open-source CAD package is described to customize the optics hardware for any application. Second, details are provided to use open-source 3-D printers (additive layer manufacturing) to fabricate the primary components and construct complex, multi-component optics-related devices. Third, the use of the open-source electronic prototyping platforms are illustrated as control devices for optics experiments. Overall, this paper describes open-source optics development, system requirements, features, advantages, and known limitations; and discuss future directions for this method of scientific hardware development to radically reduce the cost of research and science education [31].

\section{METHODOLOGY}

The process of making a 3-D computer model and then turning it into a 3-D object can be summarized as shown in Figure 1. 


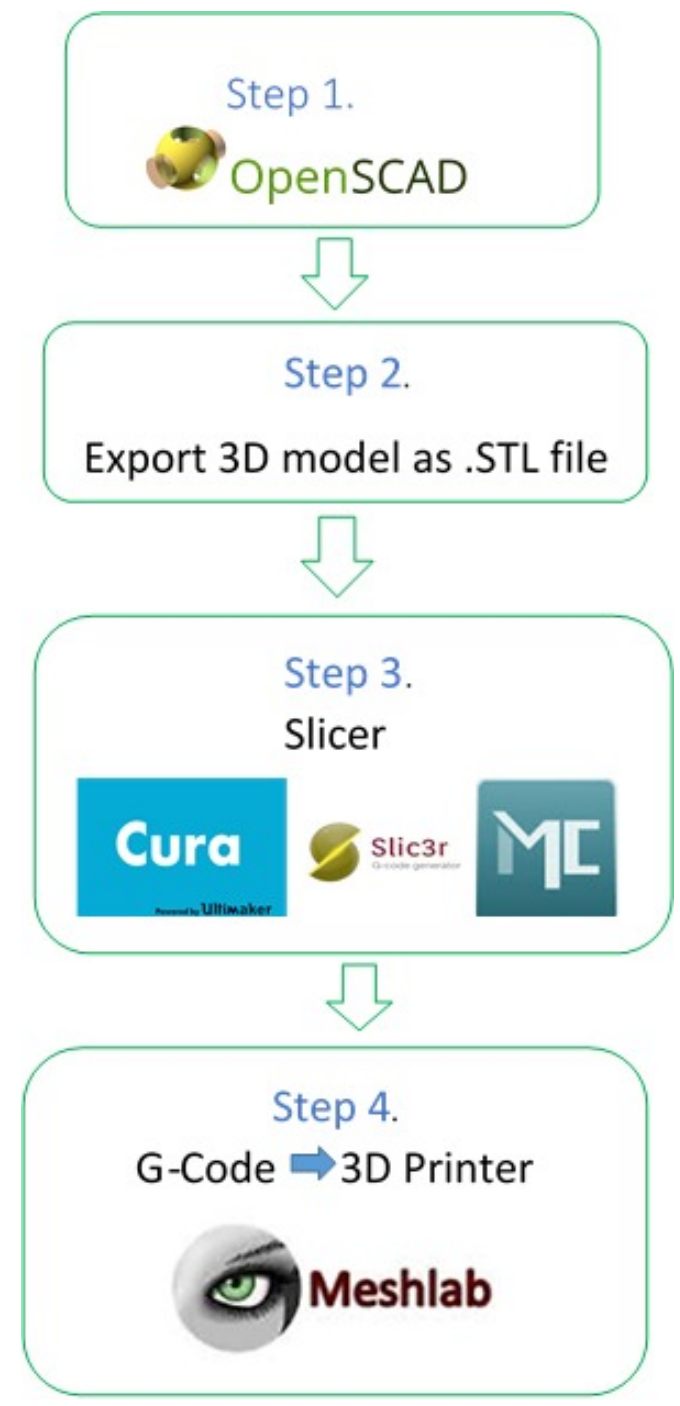

Figure 1. Generalized 3D G-code generation procedure using OpenSCAD 2013.06 and Cura 15.02. 1.

\subsection{OpenSCAD}

The optics designs evaluated here begin by being developed in OpenSCAD [52] (as shown in Figure 1) and the details are well documented $[31,52]$. OpenSCAD is an open-source, script-based computer aided design software which is freely available for Linux/UNIX, MS Windows and Mac OS X. This application focus on CAD aspects rather than artistic 3-D modelling and is ideal for applications such as creating machine parts and 3-D objects of interest. OpenSCAD is a 3D-compiler that reads in a script file that describes the object and renders the 3-D model from this script file. This gives the designer full control over the modelling process and makes it easy to change any step in the modelling process or make designs that are defined by configurable parameters (e.g. they are parametric) [31, 53]. A detailed description on modeling using OpenSCAD is provided by the open source community [53]. The designs are made to be parametric by declaring variables and then using them throughout the code. This facilitates making changes in the designs such as diameter (in case of a lens holder as shown in Figure 2-3) rather than making complex changes in the code. Changing the relevant variable results in the entire design being scaled accordingly, and new design can then be exported as a 3-D model in the form of a .STL file. The files are then sliced using an open-source slicing program such as Slic3r [54], Cura [55] or MatterSlice [56]. These slicing programs take a CAD model, slice it into layers, and output the GCode required for each layer to be 3-D printed [57]. 
Figure 2 shows an example of an OpenSCAD design for a common lens holder [31]. As OpenSCAD is computer code (similar to C) and not all users are comfortable with it there is a Customizer app that intakes OpenSCAD code and outputs a relatively easily understood GUI. Figure 3 shows the customizer view of the same 3-D design.

Figure 2. 3-D design for a lens holder in OpenSCAD 2013.06
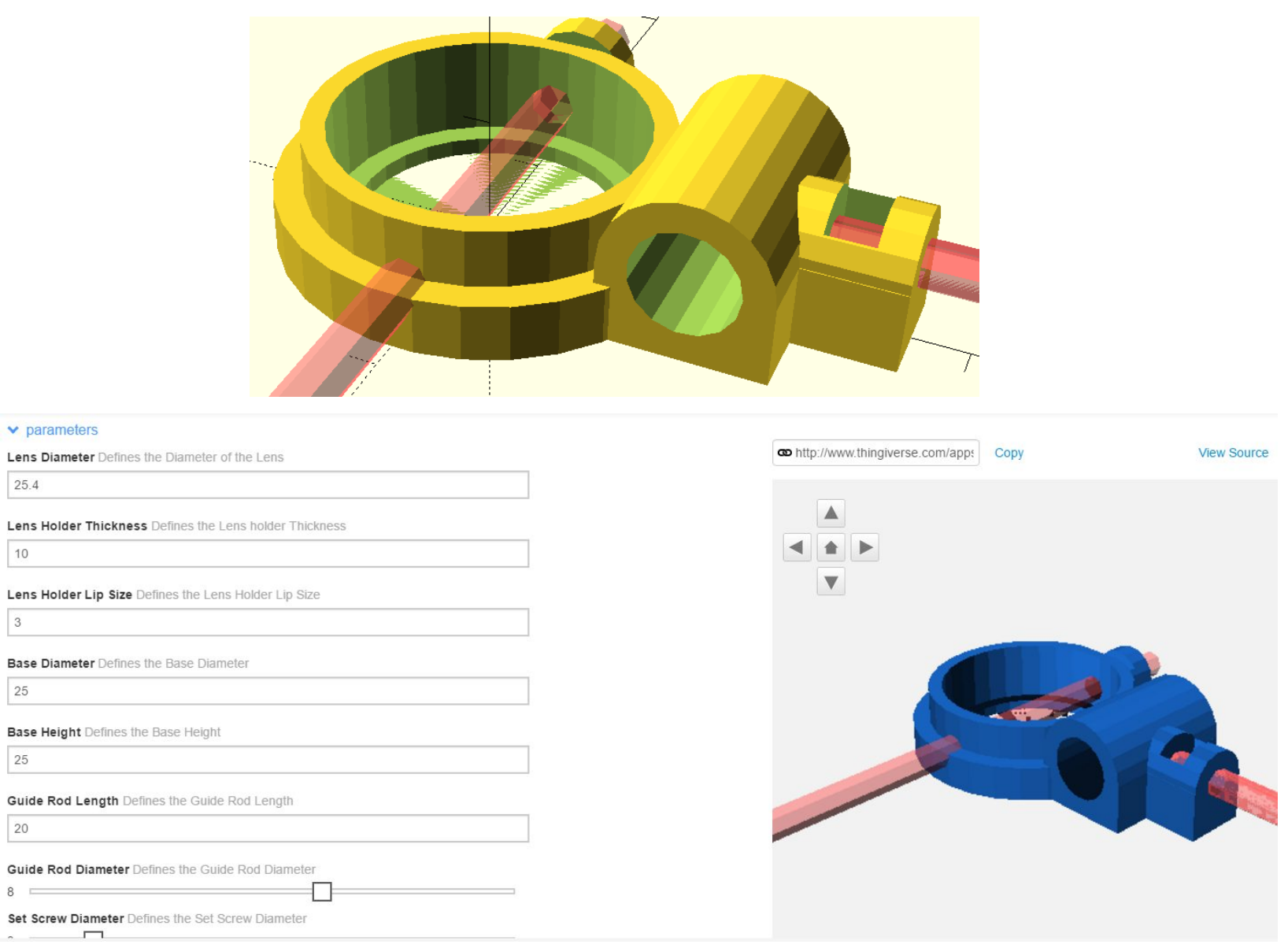

Figure 3. Lens holder 3D design opened in customizer [58, 59].

\subsection{Open-source 3-D Printing}

The g-code generated as described in Figure 1 above is loaded onto the open-source printer controller such as or Franklin [60] or printrun [61]. The objects can either be printed using polylactic acid (PLA), acrylonitrile-butadiene styrene (ABS) or other low melting point thermoplastics on any type of RepRap such as a MOST-version of the open-source RepRap Delta, or the later version called the Athena [62]. The preferred print parameters are set during slicing in Cura, slic3r or other slicing program following the path outlined in Figure 1. Figure 4 showing Cura print parameters for the lens holder. 


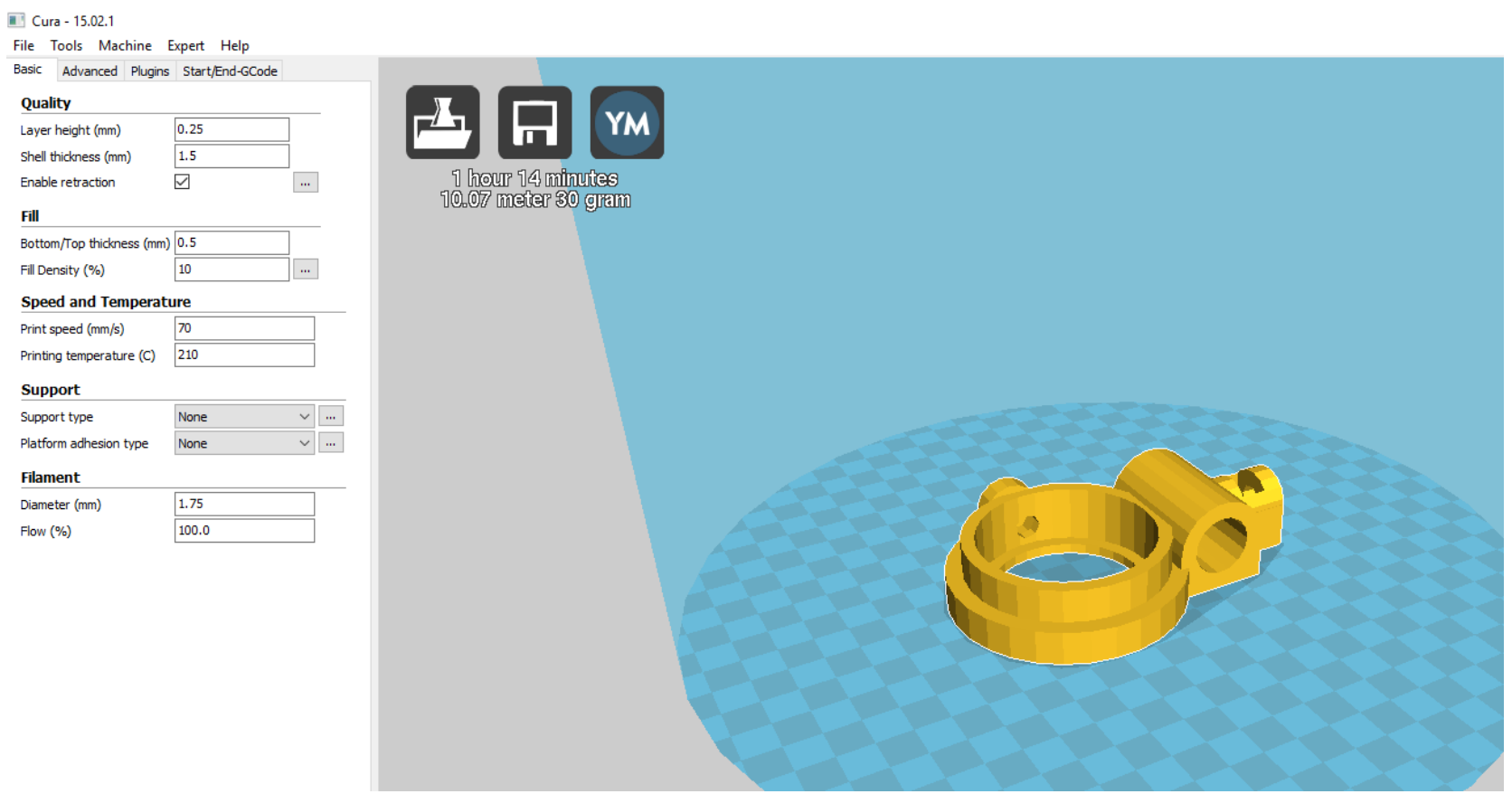

Figure 4. Lens holder print parameters shown in Cura.

The Athena RepRap 3-D printer is the improved version of the MOST Delta Printer [62], keeping all of the features that have proven to be effective and adding some new. It has the same build volume, but uses metal GT2 pulleys and GT2 timing belts with approximately twice the positioning precision of the MOST Delta. All electronics (e.g. Melzi microcontroller and Beagle Bone Green) are tucked away under the build platform and wiring management is improved with the addition of built-in passages and anchor points in idler and motor ends. This makes it easy to handle and safely transport the printer unit. The design utilizes the improved extruder drive and the MOST Delta's end effector fitted with quick release pneumatic couplers for simplified assembly and easier maintenance. The open top makes for better use of wood and removes a resonator, making the machine quieter and more flexible and even lighter to carry. Simply put, the Athena is: simpler to assemble, clean wire management, easier to maintain, offers greater flexibility, efficient use of materials, best fit for franklin and offers improved print quality [63].

\section{RESULTS AND DISCUSSION}

\subsection{Open-source 3-D Printable Optics Library}

The global open-source optics library is continuously growing with new additions of customizable printed 3-D parts being added from designers all over the world. This paper presents a few selected open-source optics lab components and more comprehensive list of components are freely available at various online repositories. The collection of both open-source optics and science equipment including source files (OpenSCAD and .STL) are thoroughly documented on Thingiverse [64] and Appropedia.org [65]. Figure 5 shows the 3-D component designs for a parametric automated filter wheel changer in different rendering settings, and Figure 6a) shows the rendered image and, 6b) is the digital photograph of the parametric automated filter wheel changer with 8 filters and 6c) another example of the same filter wheel with changed number of filters. 


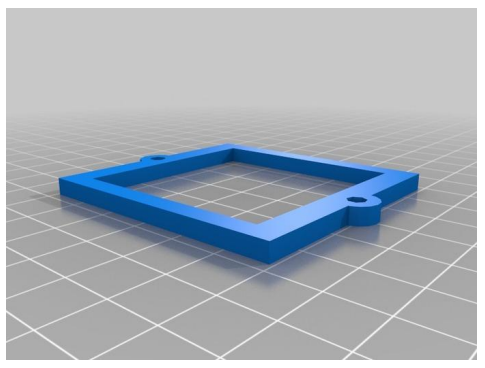

Filter bracket

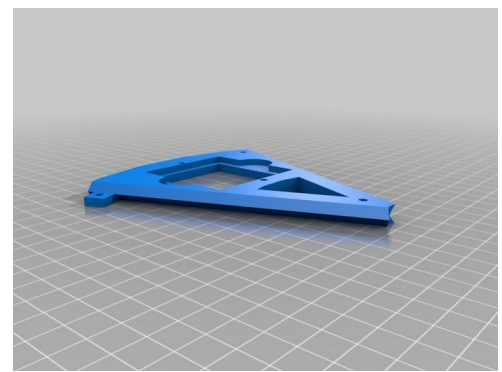

Filter wheel segment

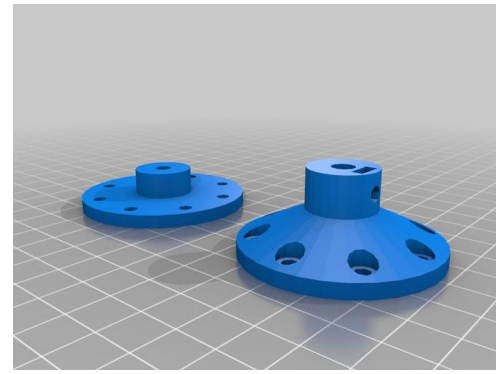

Stepper motor hub

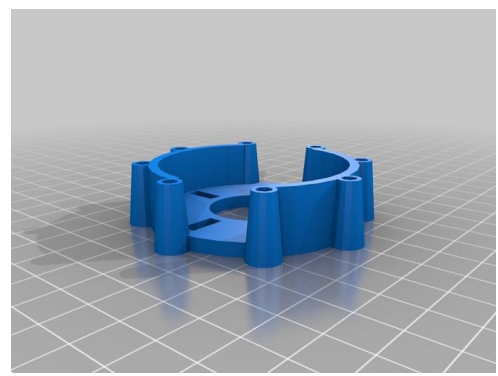

Stepper motor mount

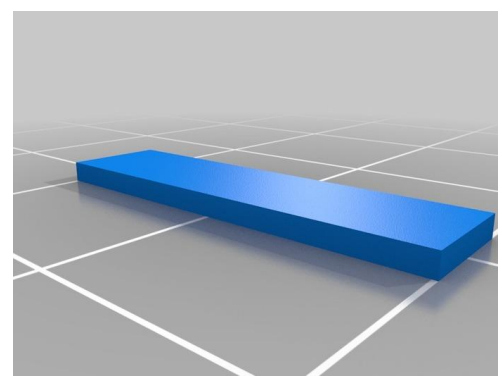

Optical switch flag

Figure 5. Parametric automated filter wheel 3-D rendered components [66].

Proc. of SPIE Vol. 10452 104522S-7

Downloaded From: https://www.spiedigitallibrary.org/conference-proceedings-of-spie on 26 Apr 2023 Terms of Use: https://www.spiedigitallibrary.org/terms-of-use 


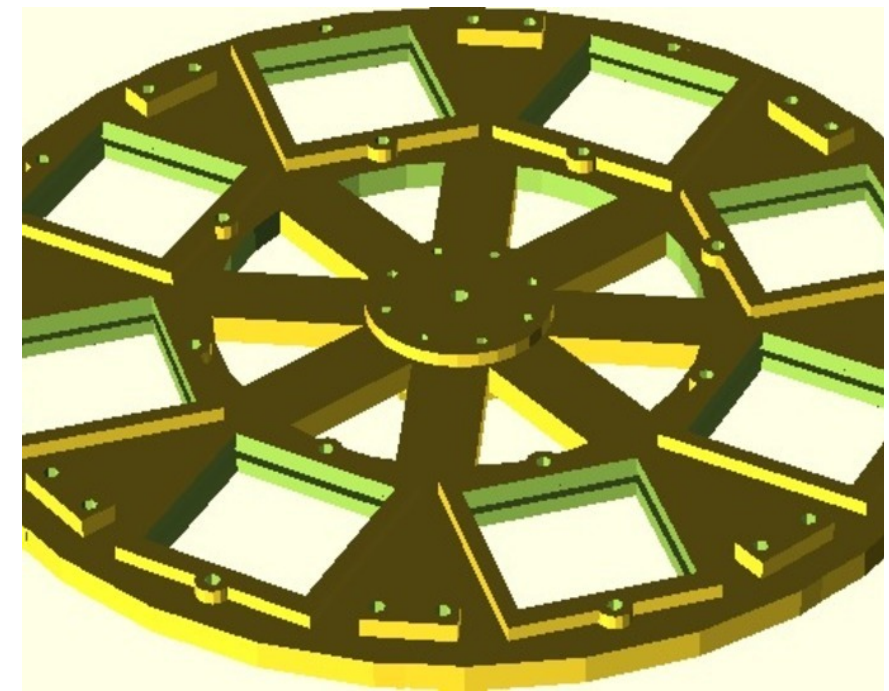

a.

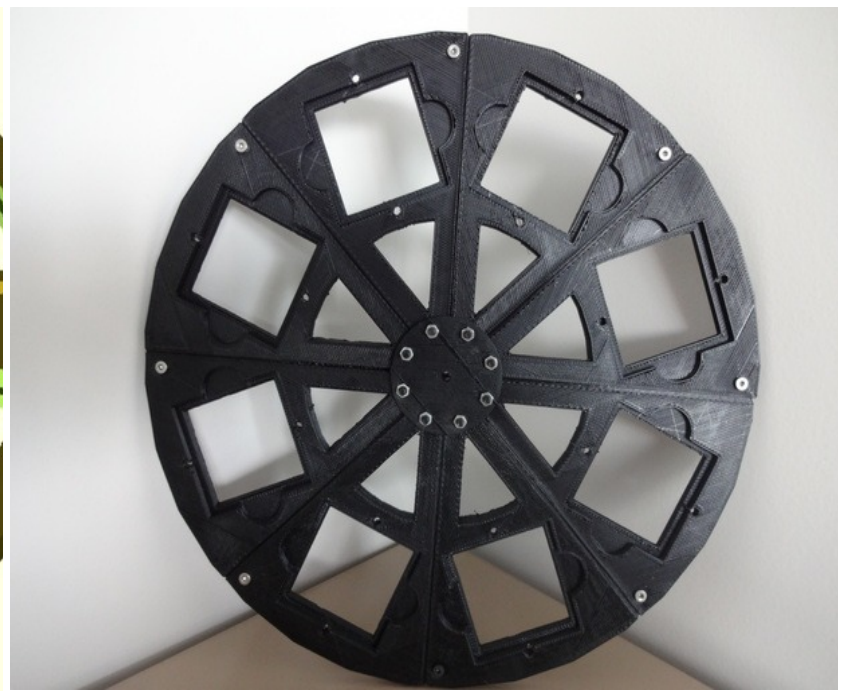

b

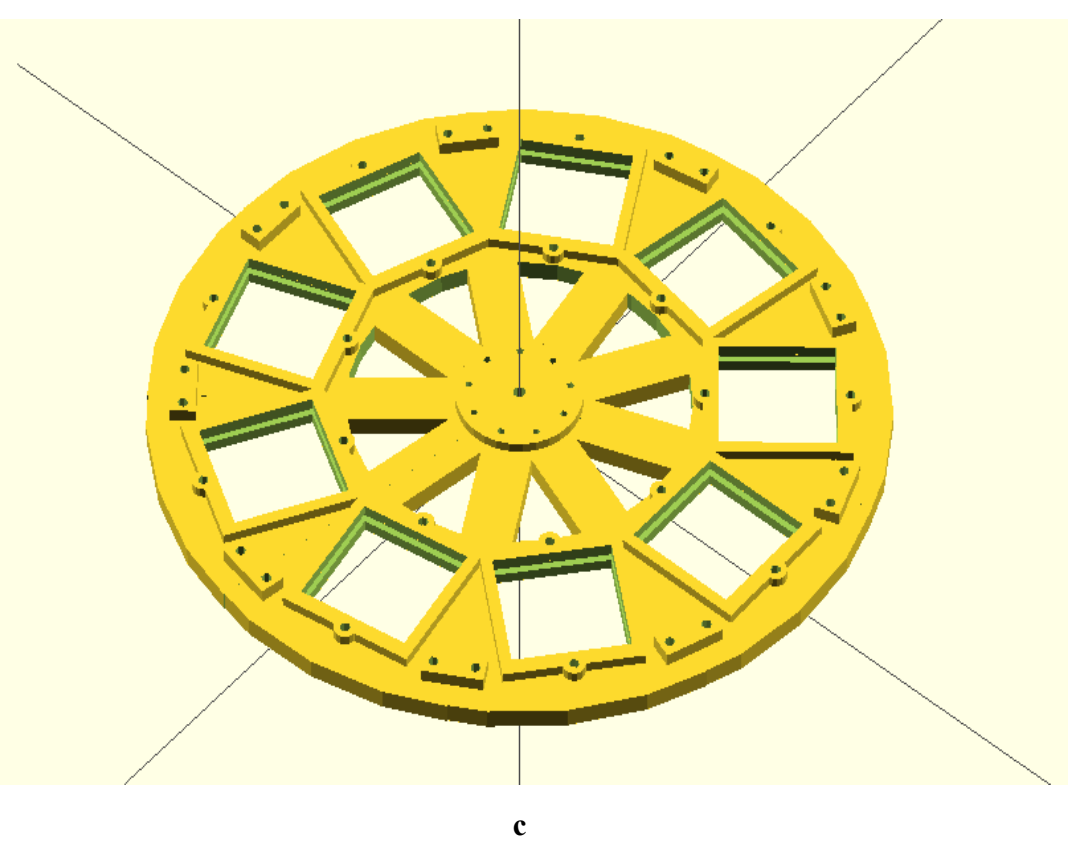

Figure 6 a) Rendered image of an 8 filter automated filter wheel and, b) digital photograph of the complete parametric automated filter wheel changer, and c) the same filter wheel rendered in OpenSCAD for 9 filters $(d=290, x=9, z=100)$ [67].As this design is parametric by changing a few parameters the filter wheel can be radically changed with minimal effort. For example in Figure $6 c$ shows the same filter wheel is shown rendered for 9 filters $(d=290, x=9, z=100)$.

OpenSCAD designs and STL files for the entire open-source optics library [64, 65] are available on several digital design repository at no cost. Any researcher, scientist, or teacher, whether professional or amateur with access to a lowcost 3-D printer can utilize the designs to radically reduce the cost of optical support equipment as summarized in Table 2 [31]. As can be seen in Table 2 cost reductions over $99 \%$ are common with only some components representing only $5 \%$ of the current commercial investment. It should be noted that these values are even better economic savings than first reported by Zhang et al. [31] in 2013. The reason this method of fabricating physics optics equipment has improved 
economically is the cost of 3-D printing filament has dropped considerably in the last 4 years as desktop 3-D printers have become more common throughout the world.

Table 2. Material and energy costs associated with open-source optics component fabrication compared to commercial prices and percent savings. The data was adapted from Zhang, et al. [31] with updated cost figures.

\begin{tabular}{|c|c|c|c|c|c|c|}
\hline Components & $\begin{array}{l}\text { Filament } \\
\text { Consumption (g) }\end{array}$ & $\begin{array}{l}\text { ABS Costs } \\
\text { USD }^{\mathrm{a}}\end{array}$ & $\mid \begin{array}{l}\text { Electricity Cost } \\
\text { USD }^{\mathrm{b}}\end{array}$ & $\begin{array}{l}\text { Total Cost } \\
\text { (USD) }\end{array}$ & $\begin{array}{l}\text { Estimated Commercial } \\
\text { Price (USD) }\end{array}$ & $\begin{array}{l}\text { Percent Savings } \\
\text { (com.-open)/com. }\end{array}$ \\
\hline Optical rail & - & - & - & $10-12 / \mathrm{m}$ & $320 / \mathrm{m}$ & 97 \\
\hline $\begin{array}{l}\text { Base on Optical Rail- optical foot (2x)- } \\
\text { optical mag (3x)- rod base }(4 x)\end{array}$ & 39.52 & 0.40 & 0.03 & 0.43 & $150-730$ & $>99$ \\
\hline Filter holder & 8.98 & 0.09 & 0.01 & 0.10 & $58-80$ & $>99$ \\
\hline Lens holder & 5.35 & 0.05 & 0.00 & 0.06 & $20-180$ & $>99$ \\
\hline Mirror holder & 7.4 & 0.07 & 0.01 & 0.08 & $18-200$ & $>99$ \\
\hline Fiber switcher & 10.41 & 0.10 & 0.01 & 0.11 & $22-138$ & $>99$ \\
\hline Screen holder & 1.55 & 0.02 & 0.00 & 0.02 & 18 & $>99$ \\
\hline Thumb screw (6x) & 7.98 & 0.08 & 0.01 & 0.09 & 12 & $>99$ \\
\hline Sample holder & 6 & 0.06 & 0.00 & 0.06 & 18-109 & $>99$ \\
\hline Lab jack & 133.2 & 1.33 & 0.11 & 1.44 & $35-1000$ & $>95$ \\
\hline Automated filter wheel changer & 295.1 & 2.95 & 0.24 & 3.19 & $1000-4250$ & $>99$ \\
\hline $\begin{array}{l}\text { Optical base }(4 \mathrm{x})+\text { steel sheet vs. } \\
\text { optical table } 1 \mathrm{~m}^{2}\end{array}$ & 46.28 & 0.46 & 0.04 & 0.50 & $3619-5288$ & $>99$ \\
\hline
\end{tabular}

\section{Notes:}

${ }^{a}$ The price of $3 \mathrm{~mm}$ ABS filament is $\$ 0.01 /$ gram [3D Printer Stuff. Available:

http://www.3dprinterstuff.com/shop/page/4?shop_param=Accessed 2017 Apr 25.].

${ }^{\mathrm{b}}$ The national average cost of electricity is $11.53 \mathrm{cents} / \mathrm{kWh}$ [US Energy Information Administration. Available:

http://www.eia.gov/beta/enerdat/\#/topic/7?agg=0,1\&geo=g\&endsec=vg\&freq=A\&start=2008\&end=2011\&charted=1 Accessed 2017

Apr 25.] and the electricity cost was derived from multimeter is $0.006925 \mathrm{kWh} / \mathrm{gram}$ (using $3 \mathrm{~mm} \mathrm{ABS}$ ) assuming a Prusa RepRap 3-

D printer.

${ }^{c}$ Commercial prices were derived from website data from various vendors including: Edmund Optics, Thorlabs, McMaster-Carr,

AutoMate Scientific, and Pasco.

\subsection{Other Open-source 3-D Printable Science Equipment}

This section discusses other open-source 3D printable science equipment in addition to optics related components details of which is documented in ref $[64,65]$. The inventory for the open-source lab ranges from hardware to automation software. Examples are shown in Figure 7 below include 7a) an automated open-source four-point probe for making sheet resistance measurements on thin films over large areas [68] and 7b) an open-source 3-D printed microscope slide holder to ease moving samples around the lab [69]. There are now literally hundreds of such tools for every area of science already available on the Internet with more being posted routinely on websites like the NIH's 3-D Print Exchange (70).

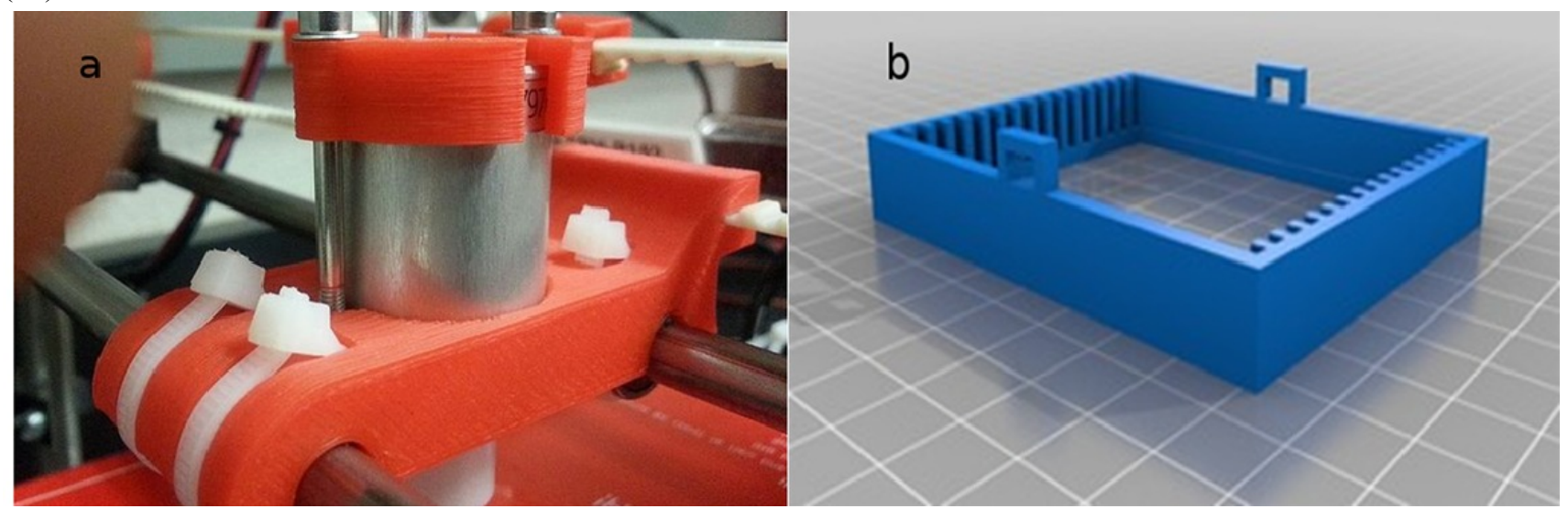

Figure 7. Examples of open-source 3-D printable science hardware showing a). Open-source four-point probe [68] and b). Open-source 3-D printed microscope slide holder [69]. 
Generally most of the 3-D printed optical components are less attractive in appearance and in precision than commercial versions. However, experimental setups particularly for high schools contain overly engineered expensive components with limited flexibility. Most of the open-source tools provide more flexibility through both customizability and the ease at which different experimental setups can be reconfigured. A clear example is eliminating an optics table in exchange for using magnetic bases and re-purposing an existing steel case desk for use in optics classes and hence reducing the setup costs while enabling far more flexibility and ease of reconfiguring an optical experimental setup [31]. The opensource optics library enables both teachers and lab technicians to design and conduct a variety of educational experiments much less expensively and easier than with conventional equipment. According to Zhang et al, [31] it would cost less than $\$ 500$ using the open-source optics approach to outfit an undergraduate teaching laboratory with 30 optics setups including $1 \mathrm{~m}$ optical tracks, optical lens, adjustable lens holder, ray optical kit, and viewing screen, the as compared to $\$ 15,000$ for commercial versions, resulting in over $\$ 14,500$ in savings. Today as shown above in Table it could be done for even less thereby saving even more. In addition to economic savings offered by the use of opensource 3-D printing, the ability to customize and locally fabricate high quality science equipment for all Science subjects (Physics, Chemistry and Biology) for all levels from elementary school through middle, high school and college education can dramatically change the way sciences are taught in schools located in resource constrained communities around the world. Empowering schools, teachers and communities with the ability to fabricate their own basic science equipment help motivate teachers and enable them to undertake effective planning for their classes.

Another interesting aspect presented here, by having the open-source optics library is that many middle school, high school and college-level experiments can be performed using designs directly downloaded from the library. An added advantage is that students within the classes and their teachers could get the opportunity to learn and used the 3-D printers to fabricate some of their own optics (or other scientific) equipment and even make or improve existing designs to suit their requirements. Ideally these students and teachers would share their designs following the open source licenses back on the web for the entire global scientific community to enjoy. This hands-on experience on designing and construction help nurture student's practical abilities and introduces them to useful engineering skills such as geometry, CAD and additive layer manufacturing as well as the open-source philosophy at an early stage in their school lives. Having scientists from all over the world download their work is also empowering and can build self-esteem [71]. These skills will be vital and can help map their future careers. Finally, the use of solar powered 3-D printers will also further expose both students and teachers to environmental friendly sources of energy such as solar energy and help off-grid communities to print their own basics science and research equipment [71]. Finally, to reduce the cost of the equipment even further recyclebots can also be used to turn post-consumer thermoplastic containers into 3-D printer filament [72, 73]. The resource poor communities could benefit greatly from 3-D printing by having the means to obtain much less costly filament, which in turn reduces 3-D printed product costs. For example recyclebots can be used to make filament from commercial PLA pellets costing approximately $\$ 5 / \mathrm{kg}$ [74]. This will further increase the cost savings and also ensure sustainability by ensuring that there is enough filament in the local market and therefore reducing the reliance on imported filament.

\subsection{Limitations of 3D printed Equipment}

There are several merits for using 3-D printed equipment for optics and basic science in general presented in this paper. However, open-source 3-D printing using low cost printers has a number of limitations. The most notable one also include the following:

(i).Prior exposure to basic software programming and skills in CAD is necessary to manipulate the 3-D printing firmware and software and to design models in OpenSCAD. Students can be taught these skills but someone at the school needs to have them.

(ii) Some hardware skills are required to assemble, operate, troubleshoot and maintain the 3-D printer units.

(iii) Basic knowledge in electrical and electronic concepts is required to maintain the 3-D printers.

(iv) The quality of the printed parts cannot be guaranteed since print quality depends on user skills and settings. This can be somewhat alleviated by following a two-step rule suggested by Tanikella et al.,[75] where 3-D printed parts that need mechanical integrity are inspected for sub-optimal printing on the outside and then 
weighed to have the mass compared to the sliced settings.

(v) The open-source optics/science designs library is not comprehensive enough yet to meet all educators' needs.

(vi) There is a number of components that cannot fabricated using the 3-D printing technology described in this paper such as lenses, beam splitters, mirrors just to mention a few.

(vii) The fundamental properties of the RepRap printer limit printed part resolution to about 100 micron steps.

(viii) Open-source low cost 3-D printed equipment is generally less precise compared to their commercially available high-end counterparts, although it often matches or exceeds the specifications of low and medium-end equipment.

\section{CONCLUSIONS}

This article describes the potential of open-source 3-D printing technology as a tool to help most schools and research institutes, particularly in the developing world build their own science and research equipment. The availability of an open-source 3-D-printable optical components library ensures easy access to a highly flexible, easy to customize, lowcost, public-domain library of both research and teaching optics hardware. There is no doubt that the 3-D printed optics equipment can go a long way in complimenting UNESCO and other organizations efforts to bring low cost science/optics kits to most developing world nations hence improving the way sciences can be taught in schools. The localized productions of customized parts and equipment have an added advantage in that it reduces the reliance on foreign donor funds and equipment made from foreign sourced materials hence adding an aspect of sustainability to the whole process. Using recyclebots to locally produce low-cost filament from recycled consumer waste can help; create local jobs, provide low cost filament, save the much needed foreign currency through import substitution and save the environment. Low-cost open-source 3-D printing technology still presents a number of limitations when used as a primary tool to put the responsibility of ensuring enough basics science kits in the hands of the stakeholders. However, preliminary results presented here show that using this open-source optics method can reduce costs of many optical components by $99 \%$, hence it creates an enabling environment for a much broader audience to participate in optical experimentation both as teaching and research platforms than previous ever anticipated using donated kits and foreign sourced proprietary equipment. The technology also shows that fabrication of more sophisticated open-source science hardware and research tools such as; automated four point probe mapping stations, spectrometers, and microscopes are possible.

\section{REFERENCES}

[1] Kvochko, E., "Five ways technology can help economies" World Economic Forum, 11 April 2013, https://www.weforum.org/agenda/2013/04/five-ways-technology-can-help-the-economy/ (20 March 2017).

[2] Gas, J. R., "Science and science education in developing countries". International Review of Education, 10(1), 77-84 (1964).

[3] Ross, A. R. and Lewin, K. M., "Science Kits in developing Countries: An Appraisal of Potential," Int. Inst. Of Education and Planning UNESCO Report. 1-120 (1992)

[4] Alarcon, M., E.A., Ben Lakhdar, Z., Culaba, I., Lakshminarayanan, V., Maquiligin J., Mazzolini A., Niemela J., Sokolff D., "UNESCO: Active Learning in Physics for Developing Countries of Asia \& Africa". World Conference on Physics and Sustainable Development. 2005: ICTP, Trieste.

[5] Ashok, P.C., "Massive Optics Outreach Event Held at ISP Chapter". SPIE Membership News. 2007.

[6] OSA. http://www.osa.org/en-us/home/ (21 March 2017).

[7] Goethe Institute. https://www.goethe.de/ins/de/en/index.html (21 March 2017).

[8] Commonwealth Secretariat. http://thecommonwealth.org/ (21 March 2017).

[9] GTZ. https://www.giz.de/en/html/index.html (21 March 2017).

[10]UNESCO. International Year of Light 2015., “ Science and Optics kit”, http://www.light2015.org/Home/HandsOnInvolvement/Science-and-Optics-Kits.html (21March 2017).

[11] Laser Classroom. "Light Blox Kit: International Year of Light Edition". http://store.laserclassroom.com/tech-light-lab-light-science-kit (21 March 2017). 
[12] Laser Classroom. "Light and Laser Education and Outreach Kit". http://store.laserclassroom.com/techlight-lab-light-science-kit (21 March 2017)

[13] Chemistry and Light School Didactica Kit. http://www.chemistryandlight.eu/ (21 March 2017).

[14] Optics Discovery Kit. USA/The Education Council of OSA. https://www.edmundoptics.com.sg/optics/optical-lenses/lens-kits/optics-discovery-kit-39140/ (21 March 2017).

[15] Optics Suitcase. USA/ROSA (Rochester section of OSA) https://www.osa.org/enus/get involved/education_outreach/optics_suitcase/optics suitcase purchase (21 March 2017).

[16] Photonics Explorer. EU/Eyest. http://www.eyest.eu/STEM-Programs/Photonics-Explorer (21 March 2017).

[17] Americal Physical society. PhysicsQuest Kit. http://www.physicscentral.com/experiment/physicsquest (21 March 2017).

[18] Galileoscope, LLC-Astrosphere New Media Association Partnership. The Galileoscope Educational Telescope Kit http://www.light2015.org/Home/HandsOnInvolvement/Science-and-Optics-Kits.html (21 March 2017).

[19] Observatory (NOAO), the International Dark-Sky Association (IDA), the International Society for Optics and Photonics (SPIE) and the International Commission on Illumination (CIE) Partnership. Teaching Kit. http://www.light2015.org/Home/HandsOnInvolvement/Science-and-Optics-Kits.html (21March 2017).

[20] World Bank. Press release: "World Bank Forecasts Global Poverty to Fall Below 10\% for First Time; Major Hurdles Remain in Goal to End Poverty by 2030", http://www.worldbank.org/en/news/pressrelease/2015/10/04/world-bank-forecasts-global-poverty-to-fall-below-10-for-first-time-major-hurdlesremain-in-goal-to-end-poverty-by-2030 (21 March 2017).

[21] Roser, M. and Ortiz-Ospina, E., "Global Extreme Poverty", Published online at OurWorldInData.org. https://ourworldindata.org/extreme-poverty/ (21 March 2017).

[22] Sells, E., Smith, Z., Bailard, S., Bowyer, A. and Olliver, V., "RepRap: the replicating rapid prototyper: maximizing customizability by breeding the means of production", Handbook of Research in Mass Customization and Personalization, Forthcoming no.1 568-580 (2010).

[23] Jones, R., Haufe, P., Sells, E., Iravani, P., Olliver, V., Palmer, C. and Bowyer, A., "RepRap-the replicating rapid prototype" Robotica, 29(01) 177-191 (2011).

[24] Bowyer, A., "3D printing and humanity's first imperfect replicator." 3D printing and additive manufacturing 1(1) 4-5 (2014).

[25] Rundle, G., "A Revolution in the Making”, Simon and Schuster (2014).

[26] Molitch-Hou, M., "RepRapPro to Reproduce 3D Printers No More", 3dprintingindustry.com, http://3dprintingindustry.com/2016/01/05/reprappro-to-reproduce-3d-printers-no-more/ (8 February 2017).

[27] Petersen, E. E. and Pearce, J. M., "Emergence of Home Manufacturing in the Developed World: Return on Investment for Open-Source 3-D Printers". Technologies 5(1), 7 (2017).

[28] Gwamuri, J., "3D Printing Technology for Economic Revolution in the developing World", The Global Scientist, April 16, 2015. http://theglobalscientist.com (7 February 2016).

[29] Gwamuri, J., Franco, D., Khan, K.Y., Gauchia, L. and Pearce, J.M., "High-Efficiency Solar-Powered 3-D Printers for Sustainable Development", Machines, 4(1), 3 (2016).

[30] King, D.L. and Babasola, A., "Mobile open-source solar-powered 3-D printers for distributed manufacturing in off-grid communities"" Challenges in Sustainability, 2(1), 18 (2014).

[31] Zhang, C., Anzalone, N.C., Faria, R. P. and Pearce, J.M., "Open-source 3D-printable optics equipment", PloS one, 8(3), e59840 (2013).

[32] Pearce, J., "Building research equipment with free, open-source hardware." Science 337, 6100 1303-1304 (2012).

[33] Pearce, J., "Maximizing return on investment for public health with open-source medical hardware", Gaceta Sanitaria 29(4) 319-319 (2015).

[34] Bergquist, M., Ljungberg, J. and Rolandsson, B., "A Historical Account of the Value of Free and Open Source Software: From Software Commune to Commercial Commons. In: Hissam. S., Russo, B. de Mendonça Neto M, Kon F, editors. Open Source Systems: Grounding Research Book Series Title: IFIP Advances in Information and Communication Technology 365. Boston: Springer. 196-207 (2011).

[35] Miller, K. W., Voas, J., Costello, T., "Free and Open Source Software", IT Professional 12: 14-16 (2010).

[36] Christian, W., Esquembre, F., Barbato, L., "Open Source Physics", Science 334: 1077-1078 (2011). 
[37] Marzullo, T.C., Gage, G. J., "The SpikerBox: A Low Cost, Open-Source BioAmplifier for Increasing Public Participation in Neuroscience Inquiry", PLoS ONE 7: e30837 (2012).

[38] Pearce, J., "The case for open source appropriate technology", Environment, Development and Sustainability 14: 425-431(2012).

[39] Pearce, J. M., Blair, C. M., Laciak, K. J., Andrews, R., Nosrat, A., and Zelenika-Zovko, I., 3-D printing of open source appropriate technologies for self-directed sustainable development. Journal of Sustainable Development, 3(4), 17 (2010).

[40] Stokstad, E., Open-Source Ecology Takes Root Across the World. Science 334: 308-309

[41] Pearce. J. M., Return on Investment for Open Source Hardware Development. Science and Public Policy (2015).

[42] Pearce, J. M., "Open-Source Lab: How to Build Your Own Hardware and Reduce Research Costs, Elsevier, (2014).

[43] Baden, T., Chagas, A. M., Gage, G., Marzullo, T., Prieto-Godino, L. L., and Euler, T., "Open Labware: 3-D Printing Your Own Lab Equipment”, PLOS Biology, 13(3) (2015).

[44] Coakley, M., and Hurt, D. E., "3D Printing in the Laboratory: Maximize Time and Funds with Customized and Open-Source Labware", Journal of laboratory automation, 21(4), 489-495 (2016).

[45]Bruns, B., "Open sourcing nanotechnology research and development: issues and opportunities," Nanotechnology 12 198-210 (2001).

[46] Mushtaq, U., and Pearce, J.M., "Open source appropriate nanotechnology”, Nanotechnology and global sustainability, 191-213 (2012).

[47]Lang, T., "Advancing global health research through digital technology and sharing data", Science, 331(6018), 714-717 (2011).

[48] Meister, S., Plouffe, D.M., Kuhen, K.L., Bonamy, G.M., Wu, T., Barnes, S.W., Bopp, S.E., Borboa, R., Bright, A.T., Che, J. and Cohen, S., "Imaging of Plasmodium liver stages to drive next-generation antimalarial drug discovery", Science, 334(6061), 1372-1377 (2011).

[49] Jones, C. J., Director, Miscellaneous Optics Corporation, interview, Sept. 23 (2011).

[50]Pearce, J. M., "3D-printing your lab equipment-it's cheaper than you think", Elsevier Connect, 2013. https://www.elsevier.com/connect/3d-printing-your-lab-equipment-its-cheaper-than-you-think (28 April 2017).

[51] Pearce, J. M., "Guest Blog: Circumventing Science Lab Budget Cuts with Open-Source Hardware", Sparkfun Education Blog. January 23, 2015. https://learn.sparkfun.com/blog/1728 (28 April 2017).

[52] OpenSCAD. Available: http://www.openscad.org (21 April 2017).

[53] http://www.openscad.org/documentation.html https://en.wikibooks.org/wiki/OpenSCAD_User_Manual/First_Steps/Creating_a simple_model (22 April 2017).

[54] http://slic3r.org/. (21 April 2017).

[55] https://ultimaker.com/en/products/cura-software (22 April 2017).

[56] http://www.mattercontrol.com (22 April 2017).

[57] http://reprap.org/wiki/G-code (22 April 2017).

[58] http://www.thingiverse.com/apps/customizer/run?thing id=62693 (22 April 2017).

[59] Wijnen, B., Anzalone, G. C., Haselhuhn, A.S., Sanders, P.G., and Pearce, J. M., "Free and Open-source Control Software for 3-D Motion and Processing," Journal of Open Research Software, 4: e2, 78 (2016).

[60] https://github.com/mtu-most/franklin/tree/master (22 April 2017).

[61] http://www.pronterface.com/ (22 April 2017).

[62] MOST. http://www.appropedia.org/Athena Build Overview (22 April 2017).

[63] Anzalone, G. C., Wijnen, B., and Pearce, J. M., "Multi-material additive and subtractive prosumer digital fabrication with a free and open-source convertible delta RepRap 3-D printer", Rapid Prototyping Journal, 21(5), 506-519 2015).

[64] http://www.thingiverse.com/jpearce/collections/open-source-optics/(22 April 2017).

[65] http://www.appropedia.org/Category:Open_source_optics; http://www.appropedia.org/Open-source_Lab (22 April 2017).

[66] Pearce, 2012: http://www.thingiverse.com/thing:26553 (22 April 2017).

[67] Parametric open-source chopper wheel. http://www.thingiverse.com/thing:28121 (21 April 2017). 
[68] Chandra, H., Allen, S. W., Oberloier, S. W., Bihari, N., Gwamuri, J., \& Pearce, J. M. (2017). Open-Source Automated Mapping Four-Point Probe. Materials, 10(2), 110 (2017).

[69] Gwamuri, J., http://www.thingiverse.com/jgwamuri/designs/page:2 (22 April 2017).

[70] https://3dprint.nih.gov/ (20 April 2017).

[71] Schelly, C., Anzalone, G., Wijnen, B. and Pearce, J.M., "Open-source 3-D printing technologies for education: Bringing additive manufacturing to the classroom". Journal of Visual Languages \& Computing. 28, 226-237 (2015).

[72] Gwamuri, J., Pearce, J. M., and Poliskey, J., "Open Source 3-D Printers: An Appropriate Technology for Developing Communities" ICAT 7, (2016).

[73] Baechler, C., DeVuono, M., and Pearce, J. M,. "Distributed recycling of waste polymer into RepRap feedstock". Rapid Prototyping Journal, 19(2), 118-125 (2013).

[74] http://www.alibaba.com/showroom/pla-resin.html (22 April 2017).

[75] Tanikella, N. G., Wittbrodt, B. and Pearce, J. M., "Tensile Strength of Commercial Polymer Materials for Fused Filament Fabrication 3-D Printing”. Additive Manufacturing, Vol. 15, 40-47 (2017). 